\title{
Keratocystic odontogenic tumor with ameloblastomatic changes mimicking dentigerous cyst: An unusual case report
}

\begin{abstract}
:
The Odontogenic Keratocystic (OKC) is a developmental cyst derived from the remanants (rest) of the dental lamina with a peculiar biological behavior. Many attempts have been made to classify these cysts from 1887 to WHO 2017 head and neck tumors. Initially classified under developmental odontogenic cyst of jaw by WHO in 1971 and 1992, OKC has then been reclassified and renamed as Keratocystic Odontogenic Tumor (KCOT) in the WHO classifications of head and neck tumors in 2005 due to its aggressive behavior, high recurrence rates and specific histopathological feature. But recently WHO 2017 classification of head and neck tumors reclassified KCOT as a cyst. Despite of so many classification and nomenclature, unfortunately the controversy still exists. KCOT has been rarely reported to transform into a more aggressive lesion like ameloblastoma. We here present a case report of KCOT involving the body and ramus of the mandible having histopathological features suggestive of ameloblastomatic changes and mimicking dentigerous cyst.
\end{abstract}

Key words: Odontogenic Keratocyst, Keratocystic Odontogenic Tumor, Ameloblastomatic changes, Dentigerous Cyst.

\section{Introduction :}

The OKC a pathological entities of the maxillofacial region was first described by Philipsen in 1956.[1] The World Health Organization classification 2005 of Head and Neck Tumors, reclassified the keratocyst as a benign neoplasm, and renamed it as "Keratocystic Odontogenic Tumor" (KCOT) defining it as "a benign uni- or multicystic, intraosseous tumour of odontogenic origin, with a characteristic lining of parakeratinized stratified squamous epithelium and potentially aggressive, infiltrative behavior which arises from the remnants of dental lamina".[2] But recently WHO 2017 classification of head and neck tumors reclassified KCOT as a cyst.

OKC have been reported to transform into primary intraosseous carcinoma (PIOSCC) or an ameloblastoma.[3] The carcinoma arising in long standing $\mathrm{OKC}$ have also been

\begin{tabular}{|l|l|}
\hline \multicolumn{3}{|c|}{ Access this article online } \\
\hline \multirow{2}{*}{$\begin{array}{l}\text { Website: } \\
\text { www.ujds.in }\end{array}$} & Quick Response Code \\
\hline $\begin{array}{l}\text { DOI: } \\
\text { https://doi.org/10.21276/10.21276/ujds.2020.6.2.7 }\end{array}$ \\
\hline
\end{tabular}

reported in several case report.[4,5] OKC and Ameloblastomaare distinct from each other. However, OKC provides the source of epithelium from which Ameloblastoma can arise[6] because the epithelial lining of OKC shares both phenotype (Ameloblastic basal layer) and gene profile (expression of enamel matrix and Odontogenic Ameloblastassociated proteins) with ameloblast-lineage cells.[7]

\section{Case Report:}

A 23-year-old male patient reported to the Outpatient Department of the Dental Institute, Rajendra Institute of

\section{${ }^{1}$ MARANDI $\mathbf{M},{ }^{2}$ SAIGAL $\mathbf{S},{ }^{3}$ NATH SINGH N \\ 1,2,3 Department of Oral Pathology, Microbiology and Forensic Odontology, Dental Institute, RIMS, Ranchi}

Address for Correspondence: Dr. Sonal Saigal Department of Oral Pathology, Microbiology and Forensic Odontology, Dental Institute, RIMS, Ranchi

E-mail: drsonalsaigal@gmail.com

Received : 15 April 2020, Published : 31 August 2020

How to cite this article: Marandi, M., Saigal, S., \& Nath Singh, N. (2020). Keratocystic Odontogenic Tumor with ameloblastomatic changes mimicking dentigerous cyst : An unusual case report. UNIVERSITY JOURNAL OF DENTAL SCIENCES, 6(2): 57-60. 
Medical Sciences (RIMS); with a chief complain of swelling associated with pus drainage from the right lower back tooth region since six months. The swelling had progressively increased in size in the right lower quadrant to involve the body and angle of the mandible. His medical history was noncontributory. On clinical examination, the patient had mild facial asymmetry with diffuse, hard, non-tender, localized swelling present in the right mandible. Intraoral examination revealed the swelling extended from 45 to 47, which measured approximately $3 \times 1 \mathrm{~cm}$, oval in shape with normal covering mucosa.

Orthopantomograph revealed well defined, solitary, multilocular, radiolucent lesion involving the body of the mandible extending from the root of 45 to the ramus of the mandible posterioly. The radiolucency extends posteriorly involving the ramus and horizontally impacted 48 at its cementoenamel junction (fig-1). Computed tomography was performed which demonstrated expansion of the buccal and lingual cortical plates with perforation of the buccal cortical plate. Fine-needle aspiration cytology (FNAC) of the lesion yielded few drops of blood, which on cytological examination revealed inflammatory cells.

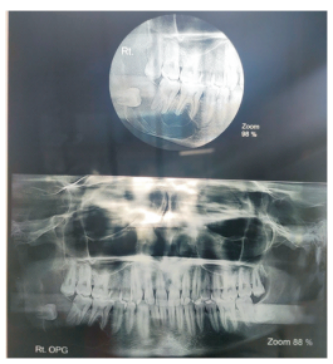

Fig. 1, Orthopatomograph showing multilocular, radiolucent lesion involving the body of the mandible

extending from the root of 45 to the ramus and horizontally impacted 48 at its cementoenamel junction

On account of clinical and radiographic findings a provisional diagnosis of Dentigerous Cyst was given. Differential diagnoses of OKC/KCOT, Ameloblastoma and Radicular Cyst were considered. Later, an incisional biopsy was performed and the tissue was fixed in neutral buffered formalin NBF for $24 \mathrm{hrs}$, and then processed and wax block was prepared. Sections of 5-6 $\mathrm{mm}$ thickness were obtained using automatic microtome which were stained by $\mathrm{H}$ and $\mathrm{E}$. On microscopic examination $\mathrm{H}$ and $\mathrm{E}$ stained section revealed corrugated parakeratinized 8-10 cell layered thick epithelium with hyperchromatic, palisading basal cells (fig-2).

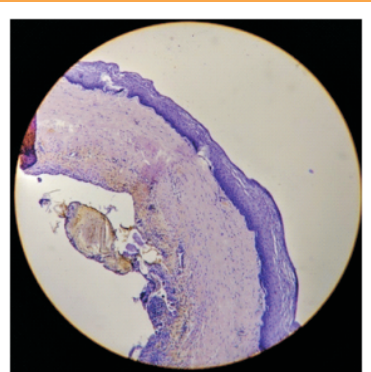

Fig. 2, Photomicrograph at 10X showing uniformly thick corrugated parakeratinized stratified squamous epithelium.

Focal area of epithelial sprout forming anastomosing pattern and island containing loosely arranged stellate reticulum like cells in the fibrocellular connective tissue stroma (fig-3).

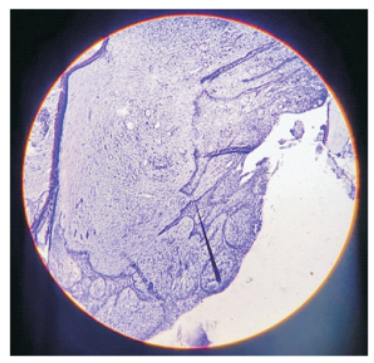

Fig. 3, Focal area of epithelial sprout forming anastomosing pattern and containing loosely Arranged stellate reticulam lick cells in the fibro cellular connective tissue stroma.

The epithelium and connective tissue interface was flat with areas of detachment of the cystic lining from the fibrous connective tissue stroma (fig-4).

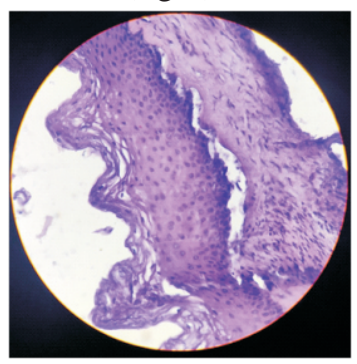

Fig-4 Showing areas of detachment of the cystic lining from the fibrous connective tissue stroma

Diagnosis of KCOT with ameloblastomatic changes was given. Surgical management of pathology was done as per the standard protocol(Belgal PG et al)8and the patient is under follow up for last six months.

\section{Discussion:}

In this case, the diagnoses that were concluded from radiographic and histopathological analysis suggested of both $\mathrm{OKC}$ and Ameloblastoma. The presence of mandibular 
radiolucency led to the differential diagnosis of $\mathrm{OKC}$, Ameloblastoma, Dentigerous Cyst. However, the incisional and excisional biopsies allowed for the definitive diagnosis of two pathologically distinct lesions: OKC and Ameloblastoma. Due to the high recurrence rate of these types of lesions [9] post-surgical follow-up is advised. OKC has a significantly higher recurrence rate in patients in the fifth decade of life $(\mathrm{P}=.005)$. Recurrence rates are significantly dependent on the sites of involvement, and OKCs in the mandibular molar region have significantly higher recurrence rates than those in other sites $(\mathrm{P}=.001)$. The histopathologic presence of one or more daughter cysts is significantly related to recurrence $(\mathrm{P}=.03)$. [10]

OKC appears radiographically as unilocular or multilocular radiolucencies, which have a thin, reactive, sclerotic bony rim with smooth or scalloped margins. These tumors may be destructive and invade into adjacent bone.[11] In contrast, Ameloblastomas are slow growing solid and cystic tumors, which are radiographically characterized as multiloculated, honeycombed, lytic lesions that are devoid of mineralization.10Radiographically, Dentigerous Cyst can be described as;

Firstly, the central variety, the tooth in which crown is enclosed by the radiolucency, with crown protruding into the cystic lumen; secondly, lateral variety in which the cyst occurs laterally along the tooth root, partially surrounding the crown; and finally, the circumferential variety which exists when the cyst not only surrounds the crown but also extends down along the root surface, thus giving the impression of the tooth within the cyst.[5] In our case the radiolucency extends posteriorly involving the ramus and horizontally impacted 48 at its cementoenamel junction. Since radiographically, lesion was found to be associated with an unerupted molar which is a typical finding regarding a Dentigerous Cyst. All these features indicated a Dentigerous Cyst.[12]

OKC have been differentiated from Ameloblastomas, Dentigerous Cysts, Radicular Cysts, Simple Bone Cysts, and Central Giant Cell Granulomas.[8] It is found that a distinctive epithelial cell proliferation in KCOT may determine its unique growth and behavior pattern. The growth pattern of KCOT epithelium is characterized by heterogeneity, and explains the infiltrative growth in OKCs in contrast to the expansive growth in other cysts.[9] Histopathology, the epithelium is distinctive with uniformly thin epithelial lining of six to eight cell layers and does not show rete ridges. This results in epithelial lifting from the fibrous connective tissue and cleft formation.[11] The superficial luminal surface of the epithelium demonstrates corrugated parakeratinized epithelium. $[11,8]$ The palisaded basal layer are hyperchromatic columnar to cuboidal cells and are described as having "picket fence" or "tomb-stone" appearance with keratinaceous material in the cystic cavity.[11,8] Epithelial islands, daughter cysts, hyaline bodies, epithelial budding of the basal layer, with dystrophic calcification have also been reported in OKC. The occurrence of two distinct odontogenic lesions in one patient is extremely uncommon.[12] Ameloblastomas have been previously reported along with an Orthokeratinized Odontogenic Cyst and a Glandular Odontogenic Cyst13 and Fregnani et al12 reported a case of Ameloblastoma and Orthokeratinized Odontogenic Cyst located on bilateral posterior regions of the mandible. In addition, Hisatomiet al14 described a case of a Glandular Odontogenic Cyst that was associated with an Ameloblastoma; the study referred to the correlation between diagnostic imaging and histopathological features. Shimamotoet al15 reported a case of ossifying fibroma and OKC.

\section{Conclusion:}

Our present case proves the possibility of the occurrence of KCOT and Ameloblastoma in mandible simultaneously and the important role of histopathological analysis to rule out the differential diagnosis. This particular knowledge should be of valuable warning as both tumors have high recurrence rate if not treated properly. Although there are no morphologic or other parameters that predict which OKC will recur or which rare $\mathrm{OKC}$ will infiltrate. Moreover $\mathrm{OKC}$ is known to have late recurrence. Therefore long-term follow-up periods are suggested for these types of tumors.

\section{References:}

1. Philipsen HP. Om keratocystomer (kolesteratomer) and kaeberneTandlaegebladet1956;60:963-71.

2. Barnes L, Eveson JW, Reichart P, SidranskyD.World Health Organization classification of tumors. Pathology and genetics of head and neck tumors. IARC Press:Lyon;2005.

3. Rajendran R. Malignant transformation of odontogenickeratocyst: A case report. Ind J Oral Max FacSurg 1999;14:24-8.

4. González-Alva P, Tanaka A, Oku Y, Yoshizawa D, Itoh S, Sakashita H. Keratocysticodontogenic tumor: A retrospective study of 183 cases. J Oral Sci 2008;50:205- 12. Article I.

5. KarikalA, ShettyT, Kudthadka A. Odontogenic Keratocyst Masquerading as a Dentigerous Cyst in the Maxilla: A Case Report of an Unusual Presentation.Eur J Ther 2018;24:121-5. Article II.

6. Gold L. Biologic behavior of ameloblastoma. Oral MaxillofacSurgClin North Am 1991;3:21-71. 
University J Dent Scie 2020; Vol. 6, Issue 2

7. Ren C, Amm HM, Devilliers P, Wu Y, Deatherage JR, Liu Z, Macdougall $M$. Targeting the sonic hedgehog pathway in keratocysticodontogenic tumor. J BiolChem 2012;287:27117-25.

8. Belgal PG, Pathak B, Shastry L. J AdvClini Research Insights 2019;6:116-8.

9. Motwani MB, Mishra SS, Anand RM, Degwekar SS, Bhowate RR. Keratocysticodontogenic tumor: Case reports and review of literature. J Indian Acad Oral Med Radiol 2011;23:150-4.

10. BaK, Li X, Wang H, Liu Y, Zheng G, Yang Z, et al. C o r r e 1 a t i o $n$ between imaging features and epithelial cell proliferation in keratocysticodontogenictumour. Dentomaxillofac Radiol 2010;39:368-74.

11. Som PM, Curtin HD. Tumors and Tumor-like Conditions. In: Head and Neck Imaging. 4th ed. Mosby, St. Louis;2003.p.347-52.

12. Fregnani ER, Cruz Perez DE, Soares FA and A 1 ves F A.S ynchronous a meloblastoma and orthokeratinizedodontogenic cyst of the mandible. J Oral Pathol Med 2006;35:573-5.

13. Grasmuck EA, Nelson BL. Keratocysticodontogenic tumor. Head Neck Patho 2010:4:94-6.

14. Hisatomi M, Asaumi J, Konouchi H, YanagiY,Kishi K.A case of glandular odontogenic cyst associated with ameloblastoma: Correlation of diagnostic imaging with histopathological features. Dentomaxillofac Radiol 2000;29:249-53.

15. Shimamoto H, Kishino M, Okura M, Chindasombatjaroen J, Kakimoto N, Murakami S, Furukawa S. Radiographic features of a patient with both cemento-ossifying fibroma and keratocysticodontogenic $\mathrm{tu}$ m or in the mandible: A case report and review of literature. Oral Surg Oral Med Oral Pathol Oral RadiolEndod 2011;112:798-802. 